\title{
ANÁLISE DA PRODUÇÃO CIENTÍFICA DOS GRUPOS DE PESQUISA EM EDUCAÇÃO EM ENFERMAGEM DA REGIÃO SUL DO BRASIL
}

\author{
Mônica Motta Lino', Vânia Marli Schubert Backes², Fabiane Ferraz³, Kenya Schmidt Reibnitz", \\ Jussara Gue Martini ${ }^{5}$
}

\footnotetext{
${ }^{1}$ Doutoranda do Programa de Pós-Graduação em Enfermagem (PEN) da Universidade Federal de Santa Catarina (UFSC). Bolsista CAPES. Santa Catarina, Brasil. E-mail: monicafloripa@hotmail.com

${ }^{2}$ Doutora em Enfermagem. Professor Associado do Departamento de Enfermagem da UFSC. Pesquisadora do CNPq. Santa Catarina, Brasil. E-mail: oivania@nfr.ufsc.br

${ }^{3}$ Doutoranda do PEN/UFSC. Bolsista de Doutorado do CNPq. Santa Catarina, Brasil. E-mail: olaferraz@yahoo.com.br

${ }^{4}$ Doutora em Enfermagem. Professor Titular do Departamento de Enfermagem da UFSC. Santa Catarina, Brasil. E-mail: kenya@ ccs.ufsc.br

${ }^{5}$ Doutora em Enfermagem. Professora do Departamento de Enfermagem da UFSC. Santa Catarina, Brasil. E-mail: jussarague@ gmail.com
}

RESUMO: Pesquisa qualitativa, exploratório-descritiva, em base documental, com o objetivo de analisar o conhecimento produzido nos Grupos de Pesquisa em Educação em Enfermagem da Região Sul do Brasil. A coleta de dados ocorreu durante o período de janeiro a maio de 2009 a partir do Censo dos Grupos de Pesquisas do Conselho Nacional de Desenvolvimento Científico e Tecnológico e no Currículo Lattes dos pesquisadores desses Grupos. A análise do conteúdo dos artigos evidenciou uma concentração de estudos de natureza qualitativa nos últimos cinco anos, pautada no positivismo, com temáticas heterogêneas e reduzido enfoque na linha de pesquisa Educação, Enfermagem e Saúde. Os enfermeiros dos Grupos têm optado pelo trabalho individual, apresentando dificuldade em articular as pesquisas entre seus membros, distanciando-se do aprofundamento em educação em saúde, preocupando-se com a categoria produtividade em detrimento de uma produção que dê visibilidade e contribua com sua linha de pesquisa.

DESCRITORES: Educação em enfermagem. Medidas, métodos e teorias. Pesquisa em educação de enfermagem. Grupos de pesquisa.

\section{SCIENTIFIC PRODUCTION ANALYSIS OF NURSING EDUCATION RESEARCH GROUPS IN SOUTHERN BRAZIL}

\begin{abstract}
The objective of this qualitative, exploratory-descriptive study, in documental base was to analyze the accumulated knowledge produced in Nursing Education Research Groups in Southern Brazil. Data was collected during the period from January to May, 2009, from the Census of the National Council of Scientific and Technological Development Research Groups and the Curriculum Lattes of these groups of researchers. Content analysis of these articles showed a concentration within the last five years in studies of a qualitative nature, based on positivism with heterogeneous themes and a reduced focus on the Education, Nursing, and Health Care line of research. The nurses of these Research Groups have opted for individual work, presenting difficulties in articulating research among their members, distancing themselves from more profound investigation in health care education, concerning themselves with the productivity category in detriment to production which gives greater visibility and contributes to their line of research.
\end{abstract}

DESCRIPTORS: Education, nursing. Measurement, methods and theories. Nursing education research. Research groups.

\section{ANÁLISIS DE LA PRODUCCIÓN CIENTÍFICA DE LOS GRUPOS DE INVESTIGACIÓN EN EDUCACIÓN EN ENFERMERÍA DE LA REGIÓN SUR DE BRASIL}

RESUMEN: Investigación cualitativa, exploratoria-descriptiva, en base documental, con el objetivo de analizar el conocimiento producido
en los Grupos de Investigación en Educación en Enfermería del Sur de Brasil. La recolección de los dados ocurrió de enero a mayo
2009, según el Censo de Grupos de Investigación del Consejo Nacional de Desarrollo Científico y Tecnológico y del Curriculum Lattes
de los investigadores de los grupos. El análisis del contenido de los artículos mostró una concentración de estudios cualitativos en los
últimos cinco años, basados en el positivismo, con diversidad de temas y escaso enfoque en la línea: Educación, Enfermería y Salud.
Los enfermeros de los Grupos han optado por el trabajo individual, con dificultad en realizar la articulación de las investigaciones
entre sus miembros, sin profundizar la educación en salud, preocupándose con la productividad en detrimento de una producción de
calidad que les de visibilidad y contribuya con su línea de investigación. DESCRIPTORES: Educación en enfermería. Mediciones, métodos y teorías. Investigación en educación de enfermería. Grupos de investigación. 


\section{INTRODUÇÃO}

Educação é um ato político na construção dos sujeitos e na transformação da realidade. Representa, pois, um processo que permite estabelecer uma relação dialética e dialógica com o contexto da sociedade à qual se destina, integrando-se nesse ambiente e aproximando-se dessa realidade, quando articulada com estratégias de ensino crítico-criativas. Assim, pode tornar-se um instrumento de transformação global dos profissionais da Enfermagem, bem como dos sujeitos-cidadãos do cuidado, visto que sua essência é pautada na reflexão, inferindo na prática da liberdade e autonomia dos sujeitos. A Educação em Enfermagem é contínua e se reflete no respeito e na ética, o que ressoa em "um ato de amor, por isso, um ato de coragem. Não pode temer o debate e a análise da realidade. Não pode fugir à discussão criadora, sob a pena de ser uma farsa". 1:104 Nesse sentido, desperta e congrega o testemunho crítico, trazendo à tona a abertura à dignidade e à esperança, por meio da libertação.

A Educação em Enfermagem é potencializadora da assistência, enriquecedora da qualidade dos serviços e fomenta a solidariedade, bem como a responsabilidade individual e coletiva, assegurando "[...] condições para humanização do homem, valorizando uma postura crítica com liberdade e criatividade, contribuindo, dessa forma, para a inserção do profissional reflexivo no mundo do trabalho". 2:23 Assim, compreende-se que a mudança na qual a Educação em Enfermagem investe permite um construir, desconstruir e reconstruir do Sistema Único de Saúde, e a orientação de políticas públicas em consonância aos interesses solidários e coletivos no Brasil.

Essa temática é tão importante para a sociedade, que existem diversos Grupos de Pesquisa em Educação em Enfermagem (GPEEs) no Brasil, objetivando partilhar e construir coletivamente saberes para um propósito maior: a transformação da realidade. Por meio de articulação social, científica, tecnológica e de extensão, os GPEEs enfrentam desafios constantes no desenvolvimento de pesquisas na área da saúde, entre eles, o próprio desconhecimento sobre como se encontra o corpo de produção científica de seus pares.

Nesse sentido, esta investigação tem como objetivo analisar o conhecimento produzido nos GPEEs da Região Sul do Brasil, a fim de elucidar como essas estruturas estão trabalhando a temática da educação na área de Enfermagem.
Ressalta-se que compreender o direcionamento e o significado da produção do conhecimento em Educação em Enfermagem, seja relacionado à ciência ou à tecnologia, é necessário para a análise de tendências pedagógicas que norteiam o ensino no setor, objetivando conhecer como se concretiza a caminhada dos pesquisadores atualmente, bem como para diagnosticar os rumos desse trajeto, relacionando criticamente qual objetivo se quer alcançar. Possibilitará, portanto, por meio do conhecimento e aprofundamento do debate sobre o panorama real de tendência das produções dos GPEEs, instigar a desestabilização para, paradoxalmente, atingir a consolidação desses espaços de saber no Brasil.

\section{METODOLOGIA}

O estudo corresponde a uma pesquisa do tipo exploratório-descritiva, em base documental, de natureza qualitativa. Desta forma, a análise dos produtos não teve fim avaliativo, mas ocorreu no sentido de apontar as tendências temáticas e tendências filosóficas embasadas nas correntes do pensamento contemporâneo adotadas nesta produção científica, com o intuito de propiciar o desenvolvimento de políticas de investigação que estimulem, expandam e consolidem essas estruturas no país.

Conforme dados coletados no Censo 2006 do $\mathrm{CNPq}$ - o último Censo disponibilizado por essa instituição - a Região Sul do Brasil possui 18 GPEEs, assim distribuídos: Rio Grande do Sul (8), Santa Catarina (3) e Paraná (7). A partir da análise do Currículo Lattes dos 173 pesquisadores cadastrados nestes GPEEs, ${ }^{3}$ foram captados todos os artigos científicos de Qualis/CAPES Internacional e disponíveis on-line no formato completo, publicados nos últimos cinco anos (2004-2008) na comunidade científica. Cumpre destacar que $95 \%$ dos currículos dos pesquisadores estavam atualizados no momento do levantamento de dados.

O período para a coleta dos dados ocorreu entre janeiro e maio de 2009. Os artigos foram organizados e sistematizados a partir do gerenciador bibliográfico EndNote ${ }^{\circledR} \mathrm{e}$, posteriormente, deram suporte a um instrumento construído para a análise dos dados. Este software exclui automaticamente toda produção duplicada, inclusive aquelas que ocorram devido à multiautoria.

A busca ativa dos estudos foi conduzida a partir de quatro etapas básicas: 1) Captação do 
estudo na íntegra; 2) Leitura dos resumos com pré-diferenciação temática e pré-diferenciação filosófica; 3) Leitura do trabalho na íntegra e diferenciação das tendências temáticas e filosóficas; e, 4) Sistematização dos estudos no instrumento de análise. Cumpre destacar que o instrumento de análise permitiu extrair dos estudos sua identificação, natureza (pesquisa qualitativa, reflexão teórica, pesquisa quantitativa, relato de experiência, revisão de literatura, entre outros), tendência temática e tendência filosófica, que, organizados no formato de tabela, foram posteriormente agrupados para ser iniciado o processo de análise temática. ${ }^{4}$

A análise de tendência temática evidencia quais temas têm sido mais e menos abordados, ou talvez ocultados, enquanto que a tendência filosófica aprofunda as evidências no sentido de compreender como os pesquisadores têm concebido seus estudos dentro de correntes de pensamento contemporâneo. É possível, portanto, evidenciar estudos de mesma temática, mas de diferentes tendências filosóficas, retratando um panorama rico, visto que existem diversas possibilidades de enfoques sobre os mais diferentes fenômenos.

Logo, analisar a tendência filosófica propicia o aprofundamento epistemológico, tendo em vista que o conhecimento científico é sempre tributário de um pano de fundo ideológico ou filosófico. Nessa perspectiva e embasada nas ideias de Triviños, ${ }^{5}$ os estudos foram classificados em três grandes tendências filosóficas, a partir da análise dos problemas de pesquisa, objetivos e intencionalidade de seus pesquisadores, hipóteses e fundamentação teórica dos estudos, conforme elucidado:

1) Positivismo: é pautada pela explicação irrefutável e verificável da realidade, por meio dos fatos observáveis. A partir de pesquisas metódicas de regras lógicas que presidem a todo enunciado correto, a única verdade - clara e imutável - vem das ciências experimentais. Juízos teológicos e filosóficos devem ser abandonados. O importante não é saber o porquê, mas o como das ciências. A pesquisa científica tem como função principal a constatação e a capacidade de prever, no entanto, a causa dos fenômenos não é função da ciência. $\mathrm{O}$ investigador estuda os fatos estabelecendo correlações e levanta como bandeira verdadeira a neutralidade da ciência. Na educação, a realidade é considerada como partes isoladas, fixas, oposta à ideia de integridade e ao pensamento dialético. ${ }^{5}$

2) Fenomenologia: trata-se de uma tendência dentro do idealismo filosófico e, dentro deste, ao idealismo subjetivo. Compreende a necessidade de reflexão da relação homem-mundo, numa postura antipositivista. Na educação, a exaltação da consciência que há nesse enfoque teórico e seu caráter a-histórico na interpretação dos fenômenos, ou seja, a omissão de conflitos de classe, da estrutura da economia, de mudanças fundamentais e necessárias, entre outras, não alcança de forma satisfatória os graves problemas das comunidades dos países subdesenvolvidos ou em desenvolvimento. O fenomenólogo estuda a realidade com o desejo de descrevê-la, de apresentá-la em sua experiência pura, sem o propósito de induzir transformações substanciais nela. ${ }^{5}$

3) Marxismo: compreende o materialismo dialético e o materialismo histórico. $\mathrm{O}$ materialismo dialético mostra como se transforma a matéria e como se realiza a passagem das formas inferiores às superiores. Já o materialismo histórico ressalta a força das ideias, capaz de introduzir mudanças nas bases econômicas que as originaram. Nessa tendência filosófica, o homem é considerado um ser social, constituído através da história. O mundo, assim, é mutável e se transforma todo o tempo. Na educação, a pesquisa marxista necessita considerar a estrutura sócio-econômica da realidade, os modos e relações de produção, classes sociais, ideologia e história da sociedade, consciência individual, cultura como fenômeno social, progresso, concepção de homem e de educação, entre outros fatores. ${ }^{5}$

Para explicar como foi realizada a classificação dos artigos, utiliza-se como exemplo um estudo com o tema - Fracasso escolar em que a delimitação do problema é - Fracasso escolar nas escolas estaduais da cidade de São José. Na concepção positivista, fenomenológica ou marxista materialismo histórico e dialético -, tanto o tema quanto a delimitação do problema são iguais, o que muda é a formulação do problema e, consequentemente, sua abordagem (Quadro 1).

Dado o tipo de desenho metodológico de investigação documental, as informações tiveram a confidencialidade correspondente, os resultados e o rigor científico da investigação qualitativa, bem como foi atentado ao compromisso com os GPEEs e instituições em dar-lhes o conhecimento dos resultados dessa pesquisa. Dessa forma, foram respeitados os preceitos éticos contidos na Resolução do CNS N¹96/96, que trata da ética de pesquisas científicas. 
Quadro 1 - Exemplo da formulação de um mesmo problema de estudo na concepção filosófica positivista, fenomenológica e marxista - materialismo histórico e dialético

\begin{tabular}{|ll|}
\hline & \multicolumn{1}{c}{ FORMULAÇÃO DO PROBLEMA } \\
Positivismo & $\begin{array}{l}\text { Existem relações entre o fracasso escolar das escolas estaduais da cidade de São José e o } \\
\text { nível sócio-econômico da família, escolaridade dos pais, posição geográfica da escola, sexo dos } \\
\text { alunos, grau de formação profissional e tempo de atuação no magistério dos professores? }\end{array}$ \\
Fenomenologia & $\begin{array}{l}\text { Como os alunos repetentes, os pais e os professores, compreendem o fracasso escolar em } \\
\text { escolas estaduais da cidade de São José? } \\
\text { Como se apresentam as relações do processo da educação referentes ao currículo, formação, } \\
\text { Marxismo }\end{array}$ \\
$\begin{array}{l}\text { desempenho profissional dos professores e posição geográfica da escola, a partir de aspectos } \\
\text { do desenvolvimento do fracasso escolar em escolas estaduais da cidade de São José? }\end{array}$
\end{tabular}

Fonte: Triviños ANS. Introdução à pesquisa em ciências sociais: a pesquisa qualitativa em educação. São Paulo: Atlas; 2006.

\section{RESULTADOS}

O montante de artigos científicos compreendidos nos últimos cinco anos (2004-2008), publicados em periódicos científicos com Qualis/ CAPES Internacional pelos GPEEs da Região Sul do Brasil e disponíveis on-line para leitura na íntegra, compuseram um universo de 330 produções. Deste total, foram evidenciadas pesquisas de natureza qualitativa $(42,0 \%)$, estudos de reflexão teórica $(23,0 \%)$, pesquisas quantitativas $(16,0 \%)$, relato de experiência $(7,0 \%)$, revisão de literatura $(7,0 \%)$ e outros $(5,0 \%)$. Artigos de natureza "outros" incluíram pesquisas qualiquantitativas e opiniões.

Os estudos foram agrupados em cinco grandes tendências, conforme afinidade temática, a saber: Cuidado em Enfermagem e Saúde; Educação em Enfermagem e Saúde; Processo de Trabalho em Saúde; Estudos Epidemiológicos; Atenção à Saúde Mental e Temas Isolados. A tendência temática Temas Isolados incluiu estudos pontuais sobre a saúde do trabalhador, conceitos da bioética, gestão e gerenciamento em saúde, pesquisa científica, qualidade de vida, direito dos usuários da saúde, relação interpessoal, atenção básica, privação da liberdade, processo de viver humano, memórias de Enfermagem e saúde do idoso (Tabela 1).

$\mathrm{Na}$ tendência temática sobre o Cuidado em Enfermagem e Saúde, os tipos de metodologias mais adotados foram Pesquisa Convergente-Assistencial (PCA) e Pesquisa-Ação para as pesquisas qualitativas de intervenção. Entre as técnicas de coleta de dados destacam-se as entrevistas semiestruturadas para as pesquisas de caracterização do cuidado ou análise de novas tecnologias cuidativas; e, por fim, questionários fechados ou análise de documentos para os estudos de natureza quantitativa.
Tabela 1 - Distribuição das tendências temáticas abordadas pelos Grupos de Pesquisa em Educação em Enfermagem da Região Sul do Brasil, 2009.

\begin{tabular}{lrr}
\hline Tendência temática & \multicolumn{1}{c}{$\mathbf{n}$} & \multicolumn{1}{c}{$\%$} \\
\hline Cuidado em enfermagem e saúde & 138 & 42,0 \\
Educação, enfermagem e saúde & 66 & 20,0 \\
Processo de trabalho em saúde & 42 & 12,5 \\
Estudos epidemiológicos & 37 & 11,2 \\
Atenção à saúde mental & 24 & 7,3 \\
Temas isolados & 23 & 7,0 \\
\hline Total & $\mathbf{3 3 0}$ & $\mathbf{1 0 0 , 0}$ \\
\hline
\end{tabular}

Fonte: Censo 2006 CNPq e Plataforma Lattes/CNPq, 2009.

Os referenciais teóricos mais adotados nesta categoria incluíram o Cuidado Transpessoal (Watson), Teoria Humanística de Enfermagem (Paterson e Zderad), Modelo de Cuidado de Carraro, Teoria do Autocuidado (Orem), Modelo de Calgary de Avaliação e Intervenção em Famílias, Teoria da Diversidade e Universalidade do Cuidado Cultural (Leininger); Teoria da Ação Comunicativa (Habermas) e a Teoria Interpretativa da Cultura (Geertz)

Os artigos contemplados nessa tendência temática são aqueles cujo enfoque ocorreu ao processo de cuidar, com referenciais específicos à análise dessa temática, o que justifica sua diferenciação de estudos que foram incluídos em outras categorias discutidas mais adiante. A maior abordagem dos estudos da tendência Cuidado em Enfermagem e Saúde tem sido sobre o cuidado à mulher, incluindo temáticas como o aleitamento materno, a prevenção ao câncer de colo uterino, o cuidado com a mulher com mastectomia, o método mãe canguru e o cuidado no trabalho de parto e puerpério. Seguido dos estudos do cuidado à mulher, os estudos de atenção à saúde mental tiveram expressão significativa, engloban- 
do enfoques de cuidado no trabalho com grupos de prevenção, no cuidado humanizado à família e às pessoas com dependência química, entre outros. Em menor expressão, foram encontrados estudos sobre cuidado com pessoas portadoras de doenças crônicas, no ambiente domiciliar, de pessoas com dor, cuidado de si, autocuidado, à criança, sobre integralidade do cuidado, humanização da assistência, tecnologias cuidativas e itinerário terapêutico.

Na tendência temática sobre Educação, Enfermagem e Saúde, as metodologias mais adotadas foram práticas educativas pautadas na problematização para estudos qualitativos, incluindo técnicas pedagógicas de redação, atividades em grupo com trabalhadores dos serviços de saúde, itinerário de pesquisa de Paulo Freire e processos educativos voltados à comunidade, ou seja, estudos de intervenção. A segunda parcela de estudos foi de reflexão teórica, pautados hegemonicamente na mudança do paradigma tradicional de educação para um processo libertador, considerando as Diretrizes Curriculares Nacionais e as concepções pedagógicas desenvolvidas na educação formal e informal. Estudos quantitativos foram inexpressivos.

O pano de fundo filosófico hegemônico nessa categoria foi o materialismo histórico-dialético, com indicação de referenciais de Paulo Freire ou de mesma perspectiva ideológica. A maior abordagem temática foi dada a estudos sobre currículo/formação e educação popular. Foram evidenciadas, em menor proporção, temáticas sobre tecnologias educacionais, educação popular, processo ensino-aprendizagem, metodologias ativas, educação permanente em saúde, educação profissionalizante, projeto político-pedagógico e processo de trabalho docente.

Já as abordagens na tendência temática Processo de Trabalho em Saúde foram sobre a Classificação Internacional das Práticas de Enfermagem em Saúde Coletiva - CIPESC, erro na administração de medicamentos, sistematização da assistência de Enfermagem e índice de satisfação do trabalho. Esses temas foram trabalhados com pressupostos da Cultura Organizacional, Teoria de Intervenção Práxica da Enfermagem em Saúde Coletiva - que é baseada no referencial materialistadialético, e também na fenomenologia.

Na tendência temática Estudos Epidemiológicos, foram adotados hegemonicamente estudos do tipo quantitativo pautados nos sistemas de informações em saúde. As temáticas trabalhadas foram diabetes, doenças cardiovasculares, doenças infecto-contagiosas, índices de hospitalização e estudos de perfil, como de traumas por acidentes de moto e de condições de saúde de agricultores, sendo que não houve interface com a temática de Educação em Enfermagem.

No tocante à tendência temática Atenção à Saúde Mental, os Grupos de Pesquisa em Educação, Enfermagem e Saúde têm trabalhado sobre reforma psiquiátrica, reabilitação psiquiátrica, drogadição, práticas culturais, política de saúde mental, desinstitucionalização e prevenção ao consumo de drogas. Muitos desses estudos estavam embasados na Teoria das Representações Sociais (Moscovici) e pressupostos fenomenológicos existenciais. Cumpre destacar que os estudos incluídos nessa tendência temática não tinham interface com a Educação em Enfermagem.

As tendências filosóficas dos estudos foram classificadas e distribuídas em três grandes correntes de pensamento contemporâneo ${ }^{5}$ : positivismo, fenomenologia e marxismo, conforme retratado na Tabela 2

Tabela 2 - Distribuição da produção científica dos Grupos de Pesquisa em Educação em Enfermagem da Região Sul do Brasil segundo tendência filosófica do pensamento contemporâneo, 2009

\begin{tabular}{lrr}
\hline Tendência filosófica & $\mathbf{n}$ & \% \\
\hline Positivismo & 209 & 63,4 \\
Fenomenologia & 86 & 26,0 \\
Marxismo & 35 & 10,6 \\
\hline Total & $\mathbf{3 3 0}$ & $\mathbf{1 0 0 , 0}$ \\
\hline
\end{tabular}

\section{DISCUSSÃO}

A produção de artigos científicos dos Grupos de Pesquisa em Educação em Enfermagem da Região Sul do Brasil não possui um foco central, revelando as mais diferentes áreas do conhecimento como produtos de suas pesquisas, conforme evidenciado nas cinco tendências temáticas. A educação vem como uma pequena parte, fomentando o debate de uma série de porquês. Por quê a maior parte da produção dos GPEEs não tem como eixo central a Educação em Enfermagem? Por quê a tendência temática mais significativa em números é a de Cuidado em Enfermagem e Saúde? Por quê a maioria dos artigos está pautada na tendência filosófica positivista? Por quê a maioria dos pesquisadores dos GPEEs, mesmo trabalhando com diferentes temáticas, não consegue estabelecer uma interface com a Educação em Enfermagem em seus 
trabalhos e, por conseguinte, nas suas produções científicas? Obviamente, para a discussão desses porquês, é coerente pensar que a questão da produtividade em pesquisa é, atualmente, uma realidade cruel no meio acadêmico das universidades, o que pode se configurar como um fator-chave que permite identificar algumas respostas.

A universidade é uma instituição social inseparável da prática republicana e democrática do Estado, cujos ideais, no entanto, podem despertar relações de conflito tendo em vista a autonomia intelectual a qual lhe é conferida. Nos últimos anos, as universidades têm sofrido mudanças - em particular, as de caráter público - com a reforma de Estado ocorrida no início dos anos 1990, que refletiram em consequências importantes ao ensino brasileiro. Depois das mudanças produzidas, a educação, a saúde e a cultura foram designadas como setores de serviços não-exclusivos do Estado, ou seja, a educação deixou de ser concebida como um direito e passou a ser considerada um serviço. Além disso, saiu da categoria de um serviço público e começou a ser considerada um serviço passível de privatização. Diante disto, esses fatores, portanto, retratam a universidade não mais como uma instituição social, mas como uma organização social.*6

Proveniente de uma análise sociológica do trabalho intelectual brasileiro nas universidades face à sociedade capitalista, acentuam-se equívocos pedagógicos à nação procedente do momento em que as atividades de pesquisa se situam no cume do sistema educacional e da hierarquização de seus pesquisadores. Neste sentido, os efeitos das políticas científicas da sociedade globalizada refletem um avanço do individualismo e da competição compulsiva, centralizando a categoria produtividade em pesquisa frente ao trabalho, às relações de trabalho e ao ensino, refletindo-se em perdas de alguns valores culturais e éticos. Destarte, há a necessidade de se pensar na consequente incapacidade que o setor de ensino brasileiro vem demonstrando de criar uma sociedade sustentável em termos de produção e consumo, de políticas públicas e convivência social, tendo em vista o desvanecer da base educacional (entenda-se como educação de base à graduação) em detrimento da alta especificidade, reduzindo a integração e inserção social e econômica. ${ }^{7}$

Nesse panorama no qual impera a produtividade e a competitividade, a alteração do próprio ensino do sistema de Pós-Graduação nos últimos vinte anos incluiu mudanças importantes. Nos anos compreendidos entre 1970 e 1980, a formação de doutores poderia perdurar por quase uma década, enquanto um título de mestrado era outorgado no prazo de quatro a seis anos. ${ }^{7}$ Atualmente, tendo em vista a compreensão mercantil da educação, atrelada à lógica da sociedade da informação sobre a do conhecimento, identifica-se um processo de formação compactada de profissionais na saúde, representados pelo encurtamento de prazos para conclusão dos cursos de doutorado e de mestrado (quatro e dois anos, respectivamente) e, ao mesmo tempo, o aumento de exigências no tocante produtividade. Além desses fatores, na área da Enfermagem, a maior parte dos profissionais se mantém trabalhando em um (ou mais) empregos, o que pode comprometer a qualidade da formação acadêmica. Assim sendo, perde-se o foco na qualidade em detrimento da quantidade de produtos científicos e tecnológicos, tendo em vista o restrito tempo disponível para o investimento em leituras, discussões e reflexões, muitas destas realizadas coletivamente, com o consequente amadurecimento de ideias e despertar crítico-criativo necessário ao processo de inovação em Educação em Enfermagem.

O enfoque socioeconômico adotado nas políticas de ensino é consequência da forma atual de capitalismo e se caracteriza pela fragmentação das esferas de vida social. Regida por contratos de gestão, alcance de metas pré-estabelecidas e índice de produtividade, frente a isso, a universidade tem concretizado uma inversão de valores: a docência passa a ser compreendida como transmissão rápida de conhecimentos e adestramento, desaparecendo sua essência na formação de qualidade. Registram-se, então, "o aumento insano de horas/ aula, a diminuição do tempo para mestrados e doutorados, a avaliação pela quantidade de publicações, colóquios e congressos, a multiplicação de comissões e relatórios, etc" 6:07

O desejo pela modernização acrítica e pouco reflexiva no sistema de trabalho e de Educação em

\footnotetext{
* A partir de inspiração francfurtiana feita por Michel Freitag em Le naufrage de l'université (Paris: Editions de la Découverte, 1996) difere-se organização de instituição por se compreender que "a instituição se percebe inserida na divisão social e política e busca definir uma universalidade (imaginária ou desejável) que lhe permita responder às contradições, impostas pela divisão. Ao contrário, a organização pretende gerir seu espaço e tempo particulares aceitando como dado bruto sua inserção num dos pólos da divisão social, e seu alvo não é responder às contradições, e sim vencer a competição com seus supostos iguais". 6:6
} 
Enfermagem são sinais de exaustão do período da pós-modernidade e reflexo da concepção positivista. Ao se pensar na atual sociedade do conhecimento frente ao próprio capital, é iniciado um processo de acumulação e repetição de produtos científicos, muitos despreocupados com o contexto social no qual se situam - o que lhes confere caráter a-histórico e, consequentemente, pouco aplicável do ponto de vista prático. O desencontro entre o que se produz e as demandas da sociedade é um viés predominante no cenário do desenvolvimento técnico-científico, desde a análise da produção dos Grupos de Pesquisa do setor Saúde no Brasil. ${ }^{8}$ Tomando esse contexto para a área de Enfermagem, o maior desafio é o desenvolvimento de pesquisas de intervenção, com pressupostos de mudanças às ações em saúde. ${ }^{9}$

Desta maneira, faz-se necessário que os GPEEs invistam em estudos de intervenção, de experimentação e avanços do ponto de vista prático, que reconheçam o contexto social dos cidadãos, como destacado por bases teóricas advindas do marxismo - materialismo histórico e dialético ${ }^{5}$. A concentração de estudos pautados no positivismo, seguido da fenomenologia, precisa ser transformada em prol de um equilíbrio no contexto da pesquisa. Importante atentar que a fenomenologia não se reduz à descrição, mas tem relação com a compreensão autêntica dos fenômenos a partir da auto-significação de si no mundo em convivência com outros. ${ }^{10}$

Os resultados revelam a dificuldade por parte dos GPEEs em articular as pesquisas entre seus pesquisadores no próprio espaço dividido para atividades do Grupo. Quando os interesses particulares predominam em detrimento de um objetivo em comum, perde-se a essência do trabalho em equipe, tão fundamental à atividade do profissional Enfermeiro. Assim, os produtos reconhecidos como trabalho coletivo de um Grupo, na verdade, são resultados de trabalhos pontuais e individuais concentrados na díade orientadororientando de Pós-Graduação, como a exemplo da importância $(11 \%)$ dada a estudos de caráter epidemiológico.

A realidade apresentada suscita uma produção desarticulada e sem respaldo das genuínas linhas de pesquisa - relacionadas à educação assumidas inicialmente pelo coletivo dos GPEEs. Este resultado corrobora com pesquisas desenvolvidas sobre a produção da Enfermagem na América Latina entre a década de 80 e início da década de 90. Naquela época já era evidenciada uma tendência marcante do Enfermeiro em realizar trabalho individual, com pouca participação de outros profissionais e a publicação de estudos hegemonicamente de caráter descritivo, com influência de correntes positivistas dominantes no campo da saúde. ${ }^{11}$

Será que a inserção de profissionais envolvidos em especialidades, como a saúde mental, nos GPEE, dificulta manter o enfoque em estudos com aderência à linha de pesquisa Educação, Enfermagem e Saúde? Esse ponto de reflexão suscita a importância da articulação de especialidades ao trabalho dos GPEE, conferindo-lhe aprofundamento e qualidade. Assim, essa proposta precisa ser orientada para que não ocorra a fuga da linha de pesquisa autêntica de seus membros, redirecionando as ações e focalizando a especialidade com aderência à temática da educação, reforçando a produção científica do setor.

A produção científica em Enfermagem tem sido motivo de preocupação disciplinar expressada por organismos internacionais como a Organização Panamericana de Saúde (OPS), a Organização Mundial de Saúde (OMS), entre outros, tendo em vista a necessidade de reconhecer o panorama da produção científica como mecanismo indispensável para obter avanços na área, enriquecer o corpo de conhecimento existente e qualificar os serviços que se prestam à sociedade. ${ }^{12-13}$

Para compreender que essa realidade não é nova, estudos desenvolvidos em relação aos eixos temáticos de abordagem das investigações em enfermagem apresentados nos Colóquios Panamericanos de Investigación en Enfermería (âmbito da América Latina), identificaram uma predominância dos anos 1980 em estudos de patologias, com enfoque biologicista. Na década de 1990, a tendência dos estudos pairou sobre os sujeitos do cuidado e dos cuidadores, com o interesse de compreender a vivência desses atores em seus processos de vida. No entanto, o maior avanço é o recente despertar para a complexidade da dimensão humana nas práticas de cuidado, desde os anos 2000, permitidos, em grande parte, pela aderência ao enfoque qualitativo das pesquisas em Enfermagem, que questiona o dogma positivista e enriquece a construção disciplinar. No entanto, os países que avançam nessas investigações - como o Brasil - precisam de mais esforços no que tange a rigorosidade de estudos qualitativos, a importância de ampliar alianças em estudos multicêntricos e em Grupos de Pesquisa para o avanço do conhecimento no setor de Educação em Enfermagem. ${ }^{13}$ 
A maioria dos estudos com enfoque positivista retrata a herança de um processo enraizado culturalmente e, em especial, dentro das academias. A mudança desse paradigma parece ocorrer de forma lenta e demonstra ser um tanto custosa dentro da universidade, o que se reflete socialmente. O próprio Cuidado de Enfermagem em Saúde parece implorar por dispositivos que insiram a humanização e a subjetividade humana no contexto, além de situar os sujeitos do cuidado como cidadãos cônscios de direitos e deveres. Talvez esse seja um dos motivos da tendência temática Cuidado em Enfermagem e Saúde ser a de maior relevância nos produtos de pesquisas dos GPEEs. Cuidado e educação são indissociáveis, pois quem cuida educa e quem educa está praticando o cuidado. Mas o puro enfoque na técnica do cuidado revela raízes biologicistas, reduzindo o cuidado a uma prática assistencial mecânica, evidenciando que o cuidado precisa, mais do que nunca, da educação, seja ela na formação inicial ou continuada, e a educação, por sua vez, é constituinte do ato de cuidado ao ser humano em sua integralidade, um enfoque que, infelizmente, não foi abordado ou discutido na maioria dos estudos apresentados nessa tendência temática.

Outro achado interessante foi que a maior parte dos estudos produzidos pelos GPEEs declara as bases teóricas nas quais se sustenta, retratando um avanço nesse sentido, mesmo sabido que as publicações não são relacionadas à educação. A teoria pode ser compreendida como "um conjunto de conceitos, sistematicamente organizados e que reflete a realidade dos fenômenos materiais sobre a qual foi construída e serve para descrever, interpretar, explicar e compreender o mundo objetivo". ${ }^{14: 122}$ Assim, as ideias são contextualizadas numa relação teórica, revelando a importante concepção da preservação da unidade teoria e prática pelos pesquisadores desses GPEEs. No entanto, cumpre destacar a importância de serem adotados referenciais críticos, que venham resgatar o debate no campo científico, já que os estudos encontram-se concentrados na descrição dos diferentes fenômenos e realidades sem discutir os diferentes porquês e sem contextualizá-los historicamente.

Nesse sentido, a intenção aqui demonstrada não se trata de pura crítica à questão da produtividade no desenvolvimento científico e tecnológico no setor de Educação em Enfermagem. Esses produtos fornecem subsídios relevantes na formulação de políticas e ações de setores específicos a serem priorizados na construção do novo, para que sejam superados os desafios na gestão de recursos públicos e, em especial, no setor saúde, que visa à melhoria da qualidade de vida da população. Isso é essencial à mudança de paradigma, essencial ao desenvolvimento do país, mas, também é necessário avançar neste discurso e partir para a constatação da importância de que sejam evidenciadas e refletidas as condições pelas quais essas produções têm sido efetivadas, bem como a temática e qualidade que têm sido produzidas - para além do quesito quantidade.

\section{CONCLUSÕES}

A análise da produção científica dos Grupos de Pesquisa em Educação em Enfermagem da Região Sul do Brasil retrata uma compreensão do propósito da congregação de ideias e do desenvolvimento de pesquisas nesses espaços, já que a estrutura de conhecimentos publicada por meio de artigos científicos nos últimos cinco anos em periódicos de Qualis/CAPES Internacional revela um distanciamento do enfoque no quesito educação. Paradoxalmente, em vez de fortalecer o processo de Educação em Enfermagem, a produção científica deste setor vem caminhando em outros sentidos, distanciando-se do aprofundamento em educação em prol da categoria produtividade.

Atualmente, resgatar o foco de trabalho dos Grupos de Pesquisa em Educação em Enfermagem é uma necessidade fundamental, sendo esse um grande e importante desafio a ser enfrentado para a consolidação dessas estruturas no Brasil. Esse processo contra-hegemônico precisa acontecer, visto que é necessário ultrapassar a teoria e avançar para concretizar a concepção libertadora de ensino, tão bem engendrada nos discursos acadêmicos. Assim, sugere-se a construção de projetos "guarda-chuvas" dentro dos GPEEs para orientar subprojetos de iniciação científica e de Pós-Graduação, mas que sejam construídos em acordo à necessidade social em saúde e educação. Mais ousado que este desafio é o investimento na articulação de projetos multicêntricos, que poderá agregar uma rede especializada em educação, fazendo emergir, possivelmente, centros de referência em Educação em Enfermagem, ainda incipientes no Brasil.

\section{AGRADECIMENTOS}

Ao CNPq, pelo apoio financeiro por meio de uma bolsa de mestrado, e ao Grupo de Pesquisas em Educação em Enfermagem e Saúde - EDEN/ 
UFSC, exemplo concreto da importância do trabalho coletivo, a partir da congregação de professores pesquisadores, acadêmicos e profissionais interessados.

\section{REFERÊNCIAS}

1. Freire P. Pedagogia da indignação: cartas pedagógicas e outros escritos. São Paulo (SP): Editora UNESP; 2000.

2. Reibnitz KS. Profissional crítico-criativo em enfermagem: a construção do espaço intercessor na relação pedagógica [tese]. Florianópolis (SC): Universidade Federal de Santa Catarina. Programa de Pós-Graduação em Enfermagem; 2004.

3. Backes VMS, Canever BP, Ferraz F, Lino MM, Prado ML, Reibnitz KS. Grupos de pesquisa em educação em enfermagem da região sul do Brasil. Rev Gaúcha Enferm. 2009 Abr-Jun; 30(2):249-56.

4. Minayo MCS. O desafio do conhecimento: pesquisa qualitativa em saúde. $8^{a}$ ed. São Paulo (SP): HUCITEC; 2004.

5. Triviños ANS. Introdução à pesquisa em ciências sociais: a pesquisa qualitativa em educação. São Paulo (SP): Atlas; 2006.

6. Chauí M. A universidade pública sob nova perspectiva. Rev Bras Educação. 2003 Set-Dez; 24(3):5-15.

7. Luz MT. Prometeu Acorrentado: análise sociológica da categoria produtividade e as condições atuais da vida acadêmica. PHYSIS: Rev Saúde Coletiva. 2005 Jan-Jun; 15(1):39-57.

8. Queiroz S, Bonacelli MBM, Mello DL, Jolô FS. O $\mathrm{CNPq}$ e o sistema de inovação em saúde no Brasil: uma análise a partir dos grupos de pesquisa do setor saúde. In: Anais do XXII Simpósio de Gestão da Inovação Tecnológica; 2002 Nov 6-8; Universidade Estadual de Campinas. Salvador: 2002:1-16.

9. Rodrigues RAP, Erdmann AL, Silva IA, Fernandes JD, Araújo TL, Vianna LAC, et al. Doctoral education in nursing in Brazil. Rev Latino-am Enfermagem. [online]. 2008 [acesso 2009 May 18]. Jul-Ago; 16(4):665-71. Disponível em: http://www.scielo. $\mathrm{br} /$ scielo.php? script=sci_arttext\&pid=S0104$11692008000400003 \& \operatorname{lng}=$ en\&nrm=iso

10. Silva JMO, Lopes RLM, Diniz NMF. Fenomenologia. Rev Bras Enferm. 2008 Mar-Abr; 61(2):254-7.

11. Manfredi M. La investigación en Enfermería en America Latina. Educ Med Salud. 1991 Abr-Jun; 25(2):154-66.

12. Cometto MC, Piovani M, Gómez P. Aportes de los Coloquios Panamericanos a la Investigación en Enfermería - período 2000-2006. Texto Contexto Enferm. 2008 Out-Dez; 17(4):720-6.

13. Malvárez SM, Agudelo-Castrillón MC. Panorama de la fuerza de trabajo en Enfermería en América Latina. Washington (US): OPS; 2005.

14. Triviños AS. A dialética materialista e a prática social. Movimento. 2006 Mai-Ago; 12(2):121-42. 